Daniels, G. (1953). J. gen. Microbiol. 8, 289-294.

\title{
The Digestion of Human Hair Keratin by Microsporum canis Bodin
}

\author{
By G. DANIELS \\ Department of Cryptogamic Botany, University of Manchester
}

SUMMARY: Microsporum canis Bodin, the causative agent of animal ringworm in children and adults, is able to digest human hair keratin in vitro. The process of degradation has been followed by microscopic observation and an analysis of the resulting amino-acids which accumulate in the medium after growth on human hair has been made by chromatographic techniques.

In this investigation attempts have been made to equate the growth of Microsporum canis Bodin on human hair with the digestion of hair keratin by the fungus. For this purpose microscopic observations of hair digestion were combined with chromatographic analyses of products which accumulate after growth of the fungus in media containing human hair. The dermatophytes are a specialized group of fungi which cause infections of the skin and dermal appendages, tissues composed principally of keratin. Although the chemical stability of keratins makes them appear to be unfavourable sources of nitrogen for living organisms, keratin digestion has been demonstrated for several organisms, notably the clothes moth (Linderstrøm-Lang \& Duspiva, 1935), the goshawk and vulture (Stanković, Arnovljević \& Matavulj, 1929), and in certain Actinomycetes (Jensen, 1930). Karling (1948) showed that certain chytrids appear to be limited to growth in keratinized tissues. The ability of ringworm fungi to grow in vitro on such tissues has long been known. Thus Bonar \& Dryer (1932), and Rogers, Hirschmann \& Humfeld (1940) cultivated various dermatophytes on wool; Macfadyen (1894), Nannizzi (1926), and Tate (1929a) on feathers; Roberts (1894), Bonar \& Dryer (1932), and Williams (1934 $a, b, 1935)$ on human and other animal hair. Growth on such complex substrata as hair, feathers and nail cannot be considered conclusive proof of the keratinophilic nature of ringworm fungi in view of the associated compounds which occur with the keratin in these materials.

When cultivating twenty-five strains of Ctenomyces, Sabouraudites, Trichophyton and Epidermophyton on single human hairs, Vanbreuseghem (1949) observed two types of hair lesion: (1) the hair was eroded over its surface as, for example, with Trichophyton rubrum; (2) fissures perpendicular to the long axis of the hair were caused by the intrusion of specialized perforating hyphae, the latter type of lesion frequently resulting in breakage of the hair shaft. By microscopic observations Page (1950) saw the disappearance of particles of finger nail and cow horn, presumably by digestion by Microsporum gypseum.

Nannizzi (1926) suggested that ringworm fungi could hydrolyse keratin; Tate $(1929 b)$, using acetone powder preparations from dermatophytes, failed 
to obtain an enzyme preparation which could hydrolyse keratin and no such enzyme has yet been isolated. Keratins are resistant to attack by proteolytic enzymes, and it may be that keratin digestion is not due to enzymic hydrolysis alone. Linderstrøm-Lang \& Duspiva (1935) showed in the larva of the clothes moth (Tineola biselliella Humm.) the occurrence of a proteolytic enzyme which, over an alkaline range of $\mathrm{pH}$ values, readily digested a reduction product of keratin, and that thiol compounds secreted into the gut of the larva were responsible for the reduction of the keratin. Nickerson (1947) suggested that the enzymes produced by the dermatophytes may be able to act only on a reduced form of keratin as do those of the clothes-moth larva.

\section{MATERIALS AND METHODS}

Human hair clippings were washed for $24 \mathrm{hr}$. in running tap water and then extracted with ether on three occasions of $2 \mathrm{hr}$. each to remove fat. Two experiments were designed: (i) in which the culture medium consisted of human hair + glucose + a simple non-nitrogenous inorganic salt solution; (ii) in which the medium consisted only of human hair + distilled water.

Exp. 1. The culture medium was prepared as follows: six $250 \mathrm{ml}$. Erlenmeyer flasks each contained $2 \mathrm{~g}$. human hair and the following solution: glucose, $0.6 \mathrm{~g}$; ; potassium dihydrogen sulphate cryst., 0.0045 g.; magnesium sulphate cryst., 0.0022 g.; $30.0 \mathrm{ml}$. distilled water. Three control flasks each contained the above solution without hair, and were sterilized by steaming for $30 \mathrm{~min}$. on three consecutive days. In the case of the six flasks containing hair, the latter was sterilized first, washed with sterile distilled water and the sterile nutrient solution added. Three of the flasks containing hair were inoculated with approximately equal amounts of hyphae of Microsporum canis Bodin; the three remaining flasks containing hair were not inoculated and were used as controls, together with those containing only nutrient solution and which were inoculated.

Exp. 2 was a replica of Exp. 1 except that the glucose + mineral salt solution was replaced by distilled water.

All the flasks were incubated at $20^{\circ}$ for 20 days. After this time considerable growth had taken place in the experimental flasks, while no growth had occurred in the control flasks containing only glucose + mineral salt solution or distilled water. The mycelium was in a healthy condition and showed no signs of collapse as observed in stale cultures. Individual hairs were removed from the experimental flasks and from uninoculated control flasks of both experiments and mounted in cotton blue lactophenol for microscopic examination.

The culture fluids were filtered through Seitz filters with sterilizing pads and the filtrates evaporated to dryness under reduced pressure, at a temperature of $25^{\circ}$. The residues were then re-dissolved in distilled water (usually $0.05 \mathrm{ml}$. or less) and samples taken for chromatographic analysis. Usually $20 \mu$ l. was used for one-dimensional chromatography and this volume also yielded satisfactory two-dimensional chromatograms. The paper partition chromatographic techniques employed were those first described by Consden, 
Gordon \& Martin (1944). Phenol was used as the first developing solvent and the butanol+acetic acid mixture of Partridge (1948) as the second. Chromatograms were dried at $100^{\circ}$ and sprayed with a solution of $0 \cdot 1 \mathrm{~g}$. ninhydrin in $100 \mathrm{ml}$. $n$-butanol saturated with water, for the detection of amino-acids. No attempt was made to separate the leucine isomers.

\section{RESULTS}

\section{Microscopic observations}

Hairs removed from control flasks and mounted in cotton blue lactophenol remained unstained and showed no signs of degradation; the cells of the cuticle showed no tendency to scale off or separate from the hair surface (Pl. 1, fig. 1). In contrast, hairs removed from experimental flasks and similarly mounted showed varying degrees of digestion. An early stage in attack is shown in Pl. 1, fig. 2; a germinating microconidium has given rise to a short hypha which has extended for some distance along the surface of the hair before penetrating and lifting up a small group of cuticular cells, together with a small number of underlying cells of the cortex. The actual method of hyphal penetration has not been established. In Pl. 1, fig. 3, stout much-branched hyphae extend along the longitudinal axis of the hair and are closely applied to the surface of the hair. Some of the finer branches terminate in minute much-branched hyphae around which localized areas of the hair take up intense stain. These may represent surface views of proliferating hyphae beneath the cuticle after initial penetration has been effected. Having gained access to the hair a process of hyphal proliferation takes place beneath the cuticle, resulting in the formation of aggregations of hyphae comprised of short much-branched segments. The pressure on the cuticle produced by the underlying aggregations of hyphae results in extensive rupture of the cuticle. The fate of the cuticle beyond this stage was difficult to ascertain. It is possible that digestion takes place in situ, although isolated cuticular cells have been observed in the medium which indicated that these cells may be sloughed off the disintegrating surface of the hair shaft. The aggregations of hyphae digest their way into the cortex of the hair forming spreading lesions of the type observed in Pl. 1, figs. $4 a, b$.

From these lesions longitudinal extension of hyphae takes place, so that these frequently connect with hyphae from other lesions, resulting in degradation of the hair until they present appearances shown in Pl. 1, figs. 5 and 6 , and Pl. 2, figs. 7-9. In some instances stout hyphae, designated by Vanbreuseghem (1949) as organs of perforation, are produced by the fungus, and these make their way into the cortex of the hair. Organs of this type were formed in two ways; (1) beneath nodules or aggregations of hyphae as a result of division and inward growth of certain segments; (2) by an inward growth of individual hyphae. They are composed of from two to ten cells (Pl. 2, fig. 10a,b). In some cases the fissures produced by perforating organs passed straight through the hair shaft, although in the main they extended only as far as the medulla. From the perforating organs longitudinal digestion of the hair 
shaft takes place, in some cases by the development of lateral branches which connect with lateral branches from other perforating organs (Pl. 2, fig. 11) and in other cases by presumed diffusion of keratin-digesting substances from the cells of the perforating organs. Anastomoses may take place between adjacent cells of perforating organs which enter the hair shaft in pairs (Pl. 2, fig. 12). Morphological features of perforating organs are best studied after clearing the hair in $\mathrm{N}-\mathrm{NaOH}$. Continuous digestion of the hair results in the disappearance of large portions of the hair shaft, leaving the original hair in fragments; the extent of this fragmentation depends on the severity of the fungal attack. The intensity with which the hairs became stained with cotton blue-lactophenol depended on the extent of hair degradation.

\section{Chromatographic analyses}

One-dimensional chromatograms indicated the presence of abundant ninhydrin-reacting substances in the culture filtrates from the experimental flasks containing hair + glucose + salt solution and their absence from both control solutions, showing that these substances had been produced during the growth of the fungus on the hair. Two-dimensional chromatograms of the filtrates from experimental flasks before and after hydrolysis with $6 \mathrm{~N}-\mathrm{HCl}$ for $24 \mathrm{hr}$. at $100^{\circ}$ were run and compared with two-dimensional chromatograms of human hair hydrolysate (prepared by heating human hair with $6 \mathrm{~N}-\mathrm{HCl}$ in sealed tubes for $24 \mathrm{hr}$. at $100^{\circ}$ ). In the chromatograms of the culture filtrate material and human hair hydrolysate the following aminoacids were identified: aspartic acid, glutamic acid, glycine, alanine, threonine, histidine, arginine, lysine, proline, tyrosine, leucine, phenylalanine, valine, serine and methionine. The identification of the spot produced by methionine was confirmed by treatment of the solution with hydrogen peroxide; in subsequent chromatograms the methionine spot had disappeared and a new spot appeared in the position of methionine sulphone. Cystine appeared in the form of cysteic acid after oxidation with hydrogen peroxide. Similar results were obtained from the filtrates of the hair + distilled water cultures except that phenylalanine, proline, tyrosine and methionine were not detected.

\section{DISCUSSION}

Microscopic observations of Microsporum canis growing on human hair are of value in investigating the ability of the fungus to digest human hair keratin. Vanbreuseghem $(1949,1950)$ described a diagnostic method, based upon the cultivation of dermatophytes on individual hairs, for the digestion of hair keratin by ringworm fungi. Visual criteria for keratin digestion give no indication of the nature of the chemical processes involved. It has been shown by chromatographic techniques in the present work that amino-acids accumulate in cultures containing human hair as sole source of nitrogen, after growth of $M$. canis for 20 days at $20^{\circ}$. The ultimate source of these amino-acids is the keratin of the hair, and it is presumed that they are produced by the digestion of hair keratin by the fungus. Evidence for this assumption is afforded by 
the similarity of the mixture of amino-acids which occurs in the media after growth of the fungus with that obtained by the hydrolysis of human hair with $6 \mathrm{~N}-\mathrm{HCl}$.

After growth of Microsporum canis on human hair in glucose + mineral salt solution, all the amino-acids occurring in human hair keratin can be detected in the medium, while after growth on human hair + distilled water, proline, tyrosine, methionine and phenylalanine were not detected. It may be that complete degradation of hair keratin occurs when a nutrient solution of glucose and non-nitrogenous mineral salts enriches the medium, and that incomplete breakdown occurs when distilled water only is added to the hair. A second explanation would be that complete degradation of the hair takes place in both cases and that complete utilization of the four amino-acids which were not detected occurs when the fungus is grown on hair + distilled water, while in glucose + mineral salt medium the four amino-acids accumulate since they are not further metabolized. Or perhaps the four amino-acids may be present in the experimental filtrates from hair + distilled water in insufficient quantities for detection in chromatograms by the ninhydrin reaction.

I am indebted to Prof. C. W. Wardlaw for encouragement and advice received during the course of this investigation, to Dr J. Curry for many valuable suggestions, and Dr A. Allsopp for advice on the use of chromatographic techniques. I am indebted to Mr E. Ashby for the photographic illustrations.

\section{REFERENCES}

Bonar, L. \& Dryer, A. D. (1932). Studies on ringworm funguses with reference to public health problems. Amer. J. publ. Hlth, 22, 909.

Consden, R., Gordon, A. H. \& Martin, A. J. P. (1944). Qualitative analysis of proteins: a partition chromatographic method using paper. Biochem. J. 38, 224.

Jensen, H. L. (1930). Decomposition of keratin by soil micro-organisms. J. agric. Sci. 20, 398.

KARLING, J. S. (1948). Keratinophilic chytrids. III. Rhizophidium nodulosum sp.nov. Mycologia, 40, 328.

Linderstrøm-Lang, K. \& Duspiva, F. (1935). Beiträge zur enzymatischen Histochemie. XVI. Die Verdauung von Keratin durch die Larven der Kleidermotte (Tineola biselliella Humm.). Hoppe-Seyl. Z. 237, 131.

Macfadyen, A. (1894). A contribution to the biology of the ringworm organism. J. Path. Bact. 3, 177.

NANnizzi, A. (1926). Ricerche sui rapporti morfologici e biologici tra Gymnoascaseae e Dermatomiceti. Ann. mycol., Berl. 24, 85.

Nickerson, W. J. (1947). Biology of Pathogenic Fungi. Waltham, Mass., U.S.A.: Chronica Botanica Co.

PAGE, R. M. (1950). Observations on keratin digestion by Microsporum gypseum. Mycologia, 42, 591.

Partridge, S. M. (1948). Filter paper partition chromatography of sugars. Biochem. $J .42,238$.

Ronerts, L. (1894). The physiology of the Trichophytons. J. Path. Bact. 3, 300.

Rogers, R. E., Hirschmann, D. J. \& Humfeld, H. (1940). Comparison of growth of Trichophyton interdigitale on wool fabric with and without additional nutritive media. Proc. Soc. exp. Biol., N.Y. 45, 729. 
Stanković, R., Arnovljević, V. \& MatavulJ, P. (1929). Enzymatische Hydrolyse des Keratins mit dem Kropsafte des Astur palumbarius (Habicht) und Vultur monachus (Kuttengeier). Hoppe-Seyl. Z. 181, 291.

TAte, P. (1929a). The dermatophytes or ringworm fungi. Biol. Rev. 4, 41.

TATE, P. (1929b). On the enzymes of certain dermatophytes or ringworm fungi. Parasitology, 21, 31.

VANBREUSEGHEM, R. (1949). La culture des dermatophytes in vitro sur des cheveux isolés. Ann. Parasit. hum. comp. 24, 559.

Vanbreuseghem, R. (1950). Diagnose et systématique des dermatophytes. Contribution à la connaissance des teignes du Congo Belge. Ann. Soc. belge. Méd. trop. 30, 865.

Williams, J. W. (1934a). Scalp products and hair as a culture medium for certain pathogenic fungi. Proc. Soc. exp. Biol., N.Y. 31, 586.

Williams, J. W. (1934b). Scalp products and hair before puberty as a culture medium for certain pathogenic fungi. Proc. Soc. exp. Biol., N.Y. 31, 944.

Williams, J. W. (1935). Scalp products and hair of men and women as culture media for certain pathogenic fungi. Proc. Soc. exp. Biol., N.Y. 32, 624.

\section{EXPLANATION OF PLATES}

\section{Plates 1 and 2}

Fig. 1. Normal, unattacked hairs from a control flask. $\times 110$.

Figs. 2-9. Stages in the digestion of human hair by Microsporum canis Bodin. Fig. 2 , $\times 660$; fig. $3, \times 330$; fig. $4 a, \times 55$; fig. $4 b, \times 165$; figs. $5,6,8$ and 9 , $\times 110$; fig. $7, \times 165$.

Figs. $10 a, b$. Perforating organs of $M$. canis Bodin within the hair shaft. $\times 660$.

Fig. 11. Perforating organ showing lateral branching within the hair shaft. $\times 165$.

Fig. 12. Anastomoses between segments of adjacent perforating organs entering the hair shaft in pairs. $\times 660$.

(Received 16 September 1952) 
Journal of General Microbiology, Vol. 8, No. 2
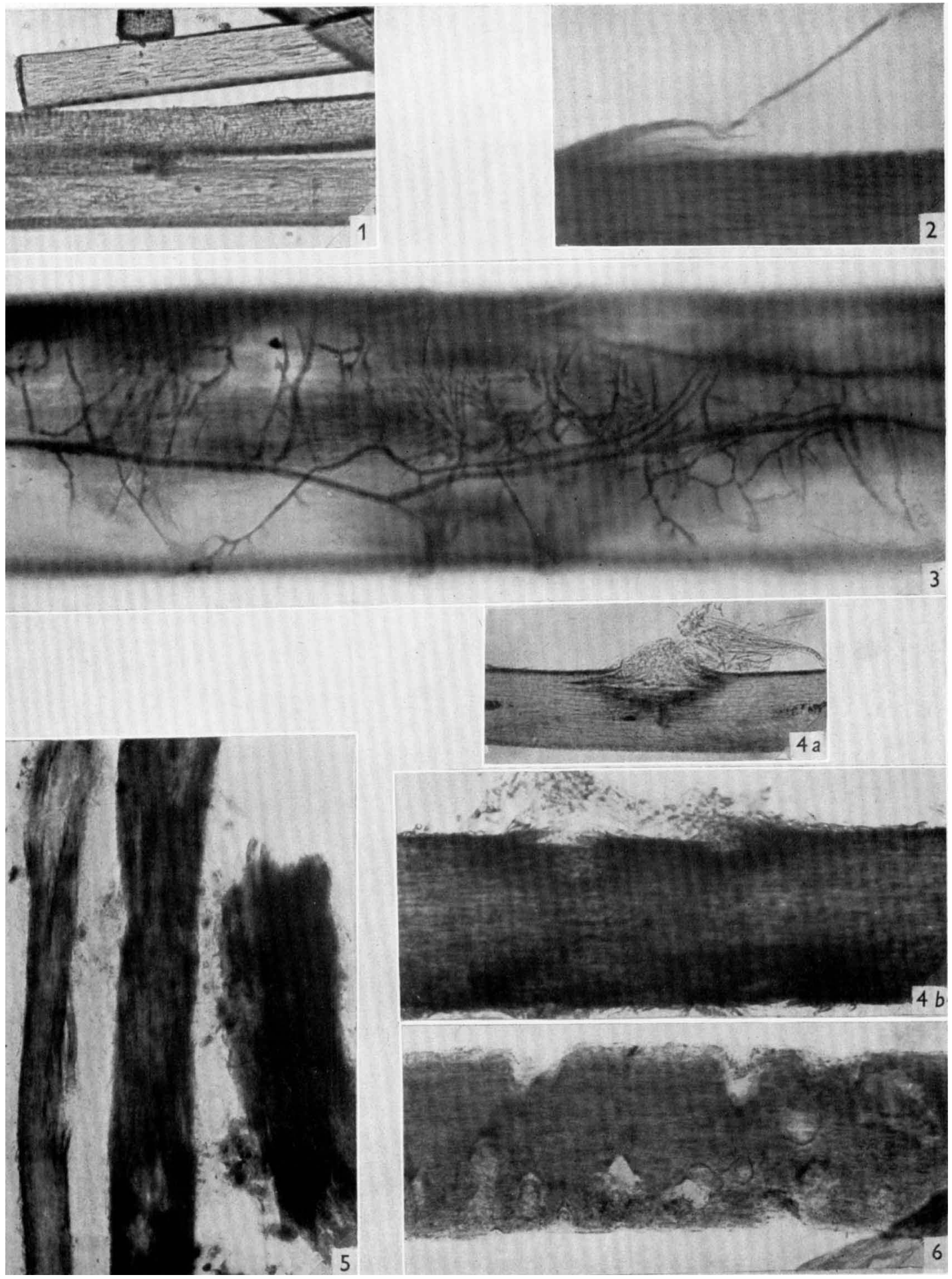

G. Daniels-Digestion of hair by Microsporum canis. Plate 1 
Journal of General Microbiology, Vol. 8, No. 2
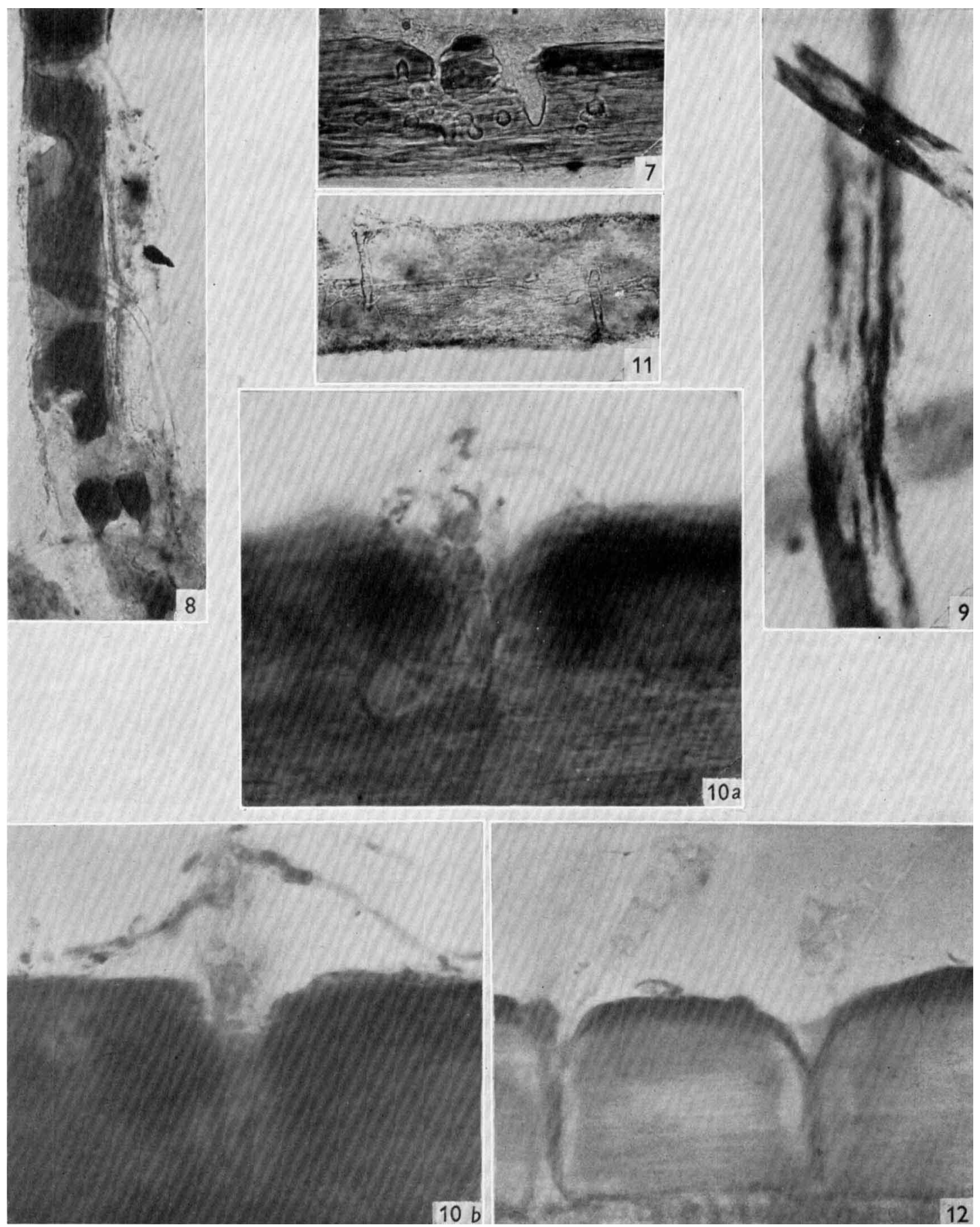

G. Daniels-Digestion of inatr by Microsporum canis. Plate 2 